\title{
Direct-Acting Antiviral Therapy Effect on Extrahepatic Rheumatic Manifestations in Egyptian Chronic Hepatitis C (HCV) Patients Mahmoud Mahmoud Yousif, Abd-Elazeim Mohammad Elhefny, Reem Abd-Elmoneim habeeb, Maryam Ahmed Abdelrahman, Rasha Nabil Thabet* \\ Department of Internal Medicine, Faculty of Medicine, Ain Shams University, Egypt \\ *Corresponding author: Rasha Nabil Thabet, Mobile: (+20)1223248583, E-mail: dr_rashanabil@ hotmail.com
}

\begin{abstract}
Background: Hepatitis $\mathrm{C}$ virus infection is an important cause of many rheumatic diseases, especially cryoglobulinemic vasculitis, fibromyalgia, arthralgia and Sicca Syndrome. Direct acting antivirals are found to be highly effective for the treatment of chronic Hepatitis C virus infection.

Objective: The aim of this study was to evaluate the clinical and serological course of extrahepatic rheumatic manifestations in chronic hepatitis C Egyptian patients after treatment with new direct-acting antivirals.

Patients and Methods: This study was carried out on 60 Egyptian patients with chronic hepatitis $\mathrm{C}$ with one or more of the HCV-related rheumatic manifestations treated with sofosbuvir (400 mg daily) plus daclatasvir (60 mg daily) as a direct-acting antivirals for 3 months. All patients were subjected to clinical and serological course of extrahepatic rheumatic manifestations evaluation.

Results: show that among the 60 patients, 21 patients $(35.0 \%)$ met the criteria of mixed cryoglobulinemia syndrome (MC), 19 patients (31.7\%) were complaining of arthralgia, 17 patients (28.3\%) were complaining of fibromyalgia and 3 patients (5.0\%) were complaining of Purpura without other criteria of mixed cryoglobulinemia syndrome. Complete clinical response was achieved in a significant number of patients with mixed cryoglobulinemia syndrome (MCS), the results also show significant clinical improvement in patients with fibromyalgia, arthralgia and purpura. Significant reduction but not complete normalization in auto-antibodies at short term follow-up was observed.

Conclusion: It could be concluded that sustained virologic response correlates with clinical and immunological improvement in most patients with extrahepatic rheumatic manifestations among the studied group of chronic hepatitis C Egyptian populations.
\end{abstract}

Keywords: Rheumatic manifestations, Hepatitis C, Direct-acting anti-viral.

\section{INTRODUCTION}

Hepatitis C virus (HCV) is infecting about 200 million people world-wide. It's main cause of morbidity and mortality ${ }^{(\mathbf{1})}$. HCV can arouse and support a clonal B-cell expansion because of its lymphotropic nature that causes numerous autoimmune/lymphoproliferative disturbances ${ }^{(2)}$.

HCV-related extrahepatic manifestations (EHM), range from benign mixed cryoglobulinemia to frank lymphomas, have been reported ${ }^{(3)}$. $\mathrm{HCV}$ infection is, also, known cause of much rheumatic illnesses, as HCV-related cryoglobulinemic vasculitis, among others ${ }^{(4)}$.

The most prevalent HCV-related rheumatic manifestations are fibromyalgia which is reported in $57 \%$ of chronic hepatitis C (CHC) patients ${ }^{(5)}$, arthralgia which is reported in $23 \%$ of CHC patients, Sicca Syndrome which is reported in $11 \%$ of CHC patients ${ }^{(\mathbf{( )}}$, and vasculitis which is reported in 5\% of $\mathrm{CHC}$ patients and represented with purpura and weakness ${ }^{(2)}$.

Auto-anti-bodies are generally utilized in the diagnosis of rheumatic illnesses pending chronic HCV infection. Levels of cryoglobulins, rheumatoid-factor (RF), and anti SSA/SSB antibodies are increased $(\leq 79 \%)$ as well as several other autoantibodies, antinuclear antibodies (ANA) $(\leq 63 \%)$, cANCA $(\leq 64 \%)$, anti- Cardiolipin $(\leq 62 \%)$, anti-DNA $(\leq 25 \%){ }^{(7)}$.
Since 2013, several new direct-acting antivirals (DAAs) have been confirmed by the United States, such new DAAs are extremely effective for the therapy of chronic HCV infection and are well tolerated with lesser side-effects ${ }^{(\mathbf{8})}$.

The treatment of extra-hepatic rheumatic troubles includes: etiological treatments with anti-viral agents aiming to removal of $\mathrm{HCV}$, pathogenetic and symptomatic approaches ${ }^{(2)}$. DAA therapies are strongly considered in the initial management of $\mathrm{HCV}$ mixed cryoglobulinemia syndrome ${ }^{\left({ }^{(9)}\right.}$. Combined/sequential therapies with anti-viral and the anti-CD20 mono-clonal anti-body (Rituximab) represent a real refinement in the treatment of most severe manifestations of $\mathrm{HCV}$-related $\mathrm{MC}^{(10)}$.

The aim of this study was to evaluate the clinical and serological course of extra-hepatic rheumatic manifestations in chronic hepatitis $\mathrm{C}$ Egyptian patients after treatment with new direct-acting anti-viral.

\section{PATIENTS AND METHODS}

This study included a total of 60 Egyptian patients with chronic hepatitis $\mathrm{C}$ with one or more of the HCVrelated rheumatic manifestations treated with sofosbuvir (400 mg daily) plus daclatasvir (60 mg daily) as a direct-acting anti-viral for 3 months. Patients 
attending at Department of Internal Medicine, Ain Shams University Hospitals.

The patients enrolled in the current study were $73.3 \%$ (44 out of 60) males and $26.7 \%$ (16 out of 60 ) females with a mean age of 55.52 years. Diagnosis of chronic hepatitis $\mathrm{C}$ was based on persistence of $\mathrm{HCV}$ antibodies and HCV-RNA in the serum of the patients for more than 6 months ${ }^{(11)}$.

Inclusion criteria: The selection of the extrahepatic rheumatic manifestations was based on their high prevalence as fibromyalgia, arthralgia, sicca syndrome and vasculitis ${ }^{(\mathbf{1 2})}$.

Exclusion criteria: Any other cause of liver disease e.g., hepatitis B, schistosomiasis, auto-immune hepatitis, alcoholic liver disease, drug-induced hepatitis, liver cirrhosis, and decompensated liver disease, severe cardiac or pulmonary disease; unstable thyroid dysfunction; psychiatric disorder; current pregnancy or breast feeding, and patients with primary rheumatological disease.

Investigations and tools utilized in the study: I - Full medical history and clinical examinations.

\section{II - Investigations:}

- Complete blood count (CBC), erythrocyte sedimentation rate (ESR), and C-reactive protein (CRP) titer by ELISA.

- Liver profile tests including total bilirubin, alanine aminotransferase, aspartate aminotransferase albumin, PT and PTT.

- Renal profile tests including creatinine, BUN, Urine analysis, and Albumin/Creatinine ratio.

- PCR for HCV RNA by quantitative method.

- Rheumatoid factor level IgM by ELISA.

- Anti-CCP antibodies level by ELISA.

- -Antinuclear antibodies (ANA) by Immunofluorescence (titer and pattern).

- Complement 3 and complement 4 levels (C3 and C4) by ELISA.

- Serum cryoglobulin by ELISA.

- Abdominal ultrasound.

Clinical Assessment of the patients:

1- Mixed cryoglobulinemia syndrome

A- Diagnosis ${ }^{(13)}$ :

Convinced at least 2 of the 3 points (questionnaire, clinical, laboratory) of the following are positive. The patient must be positive for serum cryoglobulins.

i. Questionnaire item: (at least 2 out of the following):

- Do you remember $\geq 1$ episodes of small red-spots on your skin, specially the lower limbs?

- Have you ever had red-spots on your lower extremities that quiet a brownish color after their disappearance?

- Has your doctor ever told you that you have viral hepatitis? ii. Clinical item: at least 3 out of the following 4 (present or past):

Constitutional symptoms- fatigue- arthalagiaperipheral neuropthy- articular involvememtfibromyalgia- skin ulcers-necrotizing vasculitispurpura- cranial nerve involvement- hyerviscosity syndrome- Raynaud's phenomenon- Neurologic involvement- Vasculitic CNS involvement- Fever (>38 ${ }^{\circ} \mathrm{C}$, no cause)- arthritis.

iii. Laboratory item: at least 2 out of the following 3 (present):

- Reduced serum C4.

- Positive serum rheumatoid factor.

- Positive serum M component.

B- Assessment of disease activity:

Birmingham Vasculitis Activity Score version 3 (BVAS.3) was used in our study for assessment of disease activity. It is a composite score made of 63 items organized into 10 different groups, expressing possible organ involvement. The higher the global score achieved, the more severe the disease ${ }^{(\mathbf{1 3})}$.

2-Fibromyalgia:

According to Wolfe et al. ${ }^{(14)}$ American College of Rheumatology cleared fibromyalgia diagnostic criteria in 2010.

1. Widespread pain-index (WPI) $>7$ and severity scale (SS) score $>5$ or WPI 3-6 and SS scale score $>9$.

2. Symptoms have been present at a similar level for at least 3 months.

3. The patient doesn't have a disorder that could explain the pain.

Comparison was done pretreatment and 3 months after end of treatment (post treatment) to evaluate the clinical and serological course of extrahepatic rheumatic manifestations in patients with chronic hepatitis $\mathrm{C}$ treated with new direct-acting antivirals. Also, Comparative study was done between responders and non-responders regarding both clinical and laboratory data.

\section{Ethical consent:}

An approval of the study was obtained from Ain Shams University academic and ethical committee. Each patient signed an informed, written, consent to accept the operation. This work has been conducted in accordance to The Code of Ethics of the World Medical Association (Helsinki Declaration) for studies involving humans.

\section{Statistical analysis}

The collected data were coded, processed, and analyzed utilizing SPSS (Statistical Package for Social Sciences) version-22 for Windows ${ }^{\circledR}$ (IBM SPSS Inc, Chicago, IL, USA). Data were assessed for normal distribution utilizing Shapiro Walk test. Qualitative data were presented as frequencies and percentages. Chisquare test $\left(\chi^{2}\right)$ to calculate difference between two or more groups of qualitative variables. Quantitative data were expressed as mean \pm SD (Standard deviation). 
Independent samples t-test was utilized to compare between 2-independent groups of normally distributed variables (parametric data). $\mathrm{P}$ value at level $<0.05$ was considered significant.

\section{RESULTS}

(Table 1) The patients enrolled into the present study were $44(73.3 \%)$ males and $16(26.7 \%)$ females with mean age was 55.52 years.

Table (1): Descriptive study.

\begin{tabular}{|l|c|}
\hline Age: (years) & \\
Mean \pm SD & $55.52 \pm 10.66$ \\
(range) & $(30-75)$ \\
\hline Sex: & No. $(\%)$ \\
Male & $44(73.3)$ \\
Female & $16(26.7)$ \\
\hline
\end{tabular}

Among the 60 patients, 21 patients $(35.0 \%)$ met the criteria of mixed cryoglobulinemia syndrome, 19 patients $(31.7 \%)$ were complaining of Arthralgia, 17 patients $(28.3 \%)$ were complaining of Fibromyalgia and 3 patients $(5.0 \%)$ were complaining of Purpura without other criteria of mixed cryoglobulinemia syndrome. Also at base line, among the studied patients, 34 (56.7\%) patients were positive for RF, 56 (93.3\%) patients were positive for ANA, 23 (38.3\%) patients were positive for AntiCCP and 30(50\%) patients were positive for cryoglobulin (Table 2).

Table (2): Descriptive study of rheumatological manifestations found.

\begin{tabular}{|l|c|}
\hline Rheumatic manifestation no. (\%) & \\
- Arthralgia/ Arthritis & $19(31.7)$ \\
- Fibromyalgia & $17(28.3)$ \\
- Mixed cryo & $21(35)$ \\
- Aurpura & $3(5)$ \\
- RF positive & $56(93.3)$ \\
- Anti CCP positive & $34(56.7)$ \\
- Cryoglobulin positive & $23(38.3)$ \\
\hline
\end{tabular}

There was a high statistically significant differences between immunological markers values before and after treatment in patients who had achieved SVR 12 (Table 3).

Table (3): Comparison of immunological markers values before and after treatment.

\begin{tabular}{|c|c|c|c|c|}
\hline Variables & Pre treatment values & $\begin{array}{c}\text { Post treatment } \\
\text { values }\end{array}$ & Paired t test & P value \\
\hline $\begin{array}{l}\text { RF (IU/ml) } \\
+ \text { VE NO }(\%)\end{array}$ & $42.82 \pm 4.2334(56.7)$ & $\begin{array}{c}29.61 \pm 3.54 \\
23(38.3)\end{array}$ & $Z=2.74$ & 0.006 \\
\hline $\begin{array}{l}\text { ANA }(\text { Titers < } 1 / 40) \\
1 / 40 \\
1 / 80 \\
1 / 160 \\
+ \text { VE NO }(\%)\end{array}$ & $\begin{array}{c}33(55) \\
15(25) \\
8(13.3) \\
56(93.3)\end{array}$ & $\begin{array}{c}27(45) \\
5(8.3) \\
5(8.3) \\
37(61.6)\end{array}$ & $\mathrm{FET}=33.45$ & $<0.001$ \\
\hline $\begin{array}{l}\text { Anti-CCP (U/ml.) } \\
+ \text { VE NO (\%) }\end{array}$ & $\begin{array}{c}41.96 \pm 9.70 \\
23(38.3)\end{array}$ & $\begin{array}{c}28.84 \pm 4.39 \\
16(26.6)\end{array}$ & $\mathrm{Z}=3.86$ & $<0.001$ \\
\hline $\begin{array}{l}\text { Cryoglobulin } \\
\text { +VE NO }(\%)\end{array}$ & $\begin{array}{c}1.5 \pm 0.44 \\
30(50)\end{array}$ & $\begin{array}{c}1.21 \pm 0.09 \\
21(35)\end{array}$ & $\mathrm{Z}=3.31$ & 0.001 \\
\hline $\mathbf{C 3}(\mathrm{mg} / \mathrm{dl})$ & $97.55 \pm 4.13$ & $103.32 \pm 8.95$ & 2.33 & 0.032 \\
\hline $\mathbf{C 4}(\mathrm{mg} / \mathrm{dl})$ & $21.82 \pm 11.21$ & $27.08 \pm 10.2$ & 2.78 & 0.047 \\
\hline
\end{tabular}

Birmingham Vasculitis Activity Score, as a tool for clinical response evaluation in patients with HCV related mixed cryoglobulinemia syndrome shows high statistically significant reduction after antiviral treatment (Table 4).

Table (4): Comparison of Birmingham Vasculitis Activity Score before and after antiviral treatment.

\begin{tabular}{|c|c|c|c|c|}
\hline & $\begin{array}{c}\text { Pre treatment value } \\
\text { Mean } \pm \text { SD }\end{array}$ & $\begin{array}{c}\text { Post treatment value } \\
\text { Mean } \pm \text { SD }\end{array}$ & Paired t test & P value \\
\hline BVAS.3 & $7.9 \pm 1.02$ & $3.48 \pm 0.44$ & $\mathrm{Z}=4.04$ & $<0.001$ \\
\hline
\end{tabular}

Fibromyalgia manifestations were significantly reduced after treatment as reflected by statistical significant reduction in symptom severity scale (SSS), tender points and widespread pain index (WPI) (Table 5). 
Table (5): Comparison of symptom severity scale (SSS), tender points and Widespread pain index (WPI) before and after antiviral treatment.

\begin{tabular}{|l|c|c|c|c|}
\hline \multicolumn{1}{|c|}{ Variables } & $\begin{array}{c}\text { Pre treatment values } \\
\text { Mean } \pm \text { SD }\end{array}$ & $\begin{array}{c}\text { Post treatment values } \\
\text { Mean } \pm \text { SD }\end{array}$ & $\begin{array}{c}\text { Paired t } \\
\text { test }\end{array}$ & P value \\
\hline 1- SSS & $7.91 \pm 3.18$ & $3.0 \pm 1.5$ & 14.18 & $<0.001$ \\
\hline 2- Tender point & $12.85 \pm 3.26$ & $8.77 \pm 3.77$ & 3.97 & 0.002 \\
\hline 3- WPI & $10.46 \pm 3.23$ & $8.38 \pm 3.66$ & 3.38 & 0.005 \\
\hline
\end{tabular}

There was no statistical significant differences as regards values of clinical response parameters before and after treatment in virological non responder patient (Table 6).

Table (6): Compression between clinical response parameters before and after treatment in virological non responder patients.

\begin{tabular}{|c|c|c|c|c|}
\hline Variables & $\begin{array}{c}\text { Responders post } \\
\text { treatment Mean } \pm \text { SD }\end{array}$ & $\begin{array}{c}\text { Non-responders post } \\
\text { treatment } \\
\text { Mean } \pm \text { SD }\end{array}$ & St t test & $P$ value \\
\hline Hemoglobin $(\mathrm{g} / \mathrm{dl})$ & $12.15 \pm 1.27$ & $12.19 \pm 1.03$ & 0.06 & 0.95 \\
\hline WBCs $\left(\mathrm{x} 10^{3} / \mathrm{ul}\right)$ & $6.74 \pm 2.01$ & $5.99 \pm 1.7$ & 0.95 & 0.35 \\
\hline Platelets $\left(\mathrm{x} 10^{3} / \mathrm{ul}\right)$ & $224.3 \pm 52.56$ & $209.7 \pm 35.92$ & 0.71 & 0.48 \\
\hline ESR (mm/hour) & $23.25 \pm 6.57$ & $27.14 \pm 2.97$ & 1.54 & 0.13 \\
\hline CRP (mg/L) & $10.43 \pm 2.11$ & $11.0 \pm 2.92$ & 0.34 & 0.73 \\
\hline BUN (mg/dl) & $19.3 \pm 3.31$ & $30.29 \pm 1.34$ & 3.9 & $<0.001$ \\
\hline Creatinine $(\mathrm{mg} / \mathrm{dl})$ & $0.78 \pm 0.22$ & $0.89 \pm 0.31$ & 1.17 & 0.25 \\
\hline Alb/creat ratio & $34.83 \pm 6.89$ & $47.0 \pm 6.06$ & $\mathrm{Z}=1.12$ & 0.26 \\
\hline $\begin{array}{l}\text { Urine analysis } \\
\text { Albumin+ } \\
\text { NAD }\end{array}$ & $\begin{array}{c}1(1.9) \\
52(98.1)\end{array}$ & $\begin{array}{l}1(14.3) \\
6(85.7)\end{array}$ & $\mathrm{FET}=0.36$ & 0.22 \\
\hline PCR & $0.0 \pm 0.0$ & $894428.6 \pm 496.7$ & - & - \\
\hline $\mathbf{R F}(\mathrm{IU} / \mathrm{ml})$ & $28.7 \pm 3.58$ & $33.23 \pm 4.41$ & $\mathrm{Z}=0.15$ & 0.88 \\
\hline Anti-CCP (Units) & $28.77 \pm 4.97$ & $29.4 \pm 4.85$ & 0.04 & 0.97 \\
\hline $\begin{array}{l}\text { ANA }(\text { Titers }<1 / 40) \\
1 / 40 \\
1 / 80 \\
1 / 160\end{array}$ & $\begin{array}{c}22(41.5) \\
6(11.3) \\
4(7.5)\end{array}$ & $\begin{array}{l}3(42.9) \\
1(14.3) \\
1(14.3)\end{array}$ & $\begin{array}{l}\text { Mc Nemar } \\
\text { test }\end{array}$ & 0.11 \\
\hline Cryoglobulin & $1.02 \pm 0.09$ & $1.73 \pm 0.7$ & $\mathrm{Z}=1.22$ & 0.14 \\
\hline $\mathbf{C 3}(\mathrm{mg} / \mathrm{dl})$ & $103.77 \pm 3.19$ & $99.86 \pm 8.14$ & 0.33 & 0.74 \\
\hline $\mathbf{C 4}(\mathrm{mg} / \mathrm{dl})$ & $27.49 \pm 1.3$ & $24.0 \pm 5.54$ & 0.85 & 0.40 \\
\hline
\end{tabular}

\section{DISCUSSION}

Viral hepatitis accounted for 1.45 million deaths in 2013 that increased compared with 0.89 million deaths in 1990. Morbidity also increased in terms of years lived with disability from 0.65 million to 0.87 million and disability-adjusted life-years; from 31.7 million to 42.5million ${ }^{(15-17)}$.

The landscape of antiviral therapy in HCVinfected patients has changed dramatically with the new direct-acting anti-virals (DAAs) ${ }^{(\mathbf{1 8})}$.

In large cohort studies, 2/3 of patients with $\mathrm{HCV}$ infection showed extra-hepatic manifestations (EHM) (17). Due to its lymphotropism, HCV induces B-cells, and promotes appropriate conditions for B-lymphocyte proliferation, leading to $\mathrm{HCV}$-related autoimmune or lymphoproliferative disorders ${ }^{(\mathbf{1 9})}$.

The aim of this study was to evaluate the clinical and serological course of extra-hepatic rheumatic manifestations in chronic hepatitis C Egyptian patients after treatment with new direct-acting anti-viral.
The present study was conducted on 60 Egyptian patients with chronic hepatitis $\mathrm{C}$ suffering clinically from of one or more of the HCV- related rheumatic manifestations and eligible for treatment with sofosbuvir (400 mg daily) plus daclatasvir (60mg daily) as a directacting anti-viral for 3 months.

The rate of occurrence of rheumatic manifestations in our patients was $8.2 \%$ (60 out of 732); this agrees with results of Sayiner $\boldsymbol{e t}$ al. ${ }^{(20)}$, who cleared that rheumatologic extra-hepatic manifestations are found in 2\%-38\% of $\mathrm{HCV}$-infected patients. This variability is expected to the differences in the geographical region and study design.

In the present study, 35\% (21 out of 60) of patients met the criteria of Mixed cryoglobulinemia syndrome (MCS), 31.7\% (19 out of 60) of patients were complaining of Arthralgia, 28.3\% (17 out of 60) of patients were complaining of fibromyalgia and $5 \%$ (3 out 
of 60) of patients were complaining of Purpura without other criteria of MCS.

Regarding sustained virological response (SVR); the goals of antiviral treatment in patients with $\mathrm{HCV}$ related rheumatic manifestations are not only achieving SVR, but also symptomatic response of rheumatic manifestations and minimization of the use of immunosuppressive therapies ${ }^{(\mathbf{1 5})}$.

Regarding the clinical response to DAAs in patients with MCS at short term follow up, the current study shows that complete clinical response was achieved in $38 \%$ ( 8 out of 21 ) of patients, with significant reduction of the overall BVAS.v3 from 7.9 points at baseline to 3.48 at SVR 12 (P < 0.001); this came in accordance with a study of Bonacci $\boldsymbol{e t}$ al. ${ }^{(15)}$ and Gragnani et al. (21), who reported that 34\% were complete responders and cleared all manifestations of vasculitis, with significant reduction of the mean BVAS.v3 from 5.41 points at baseline to 2.35 at week 4 on treatment to 1.39 at SVR12 $(\mathrm{P}<0.001)$.

Regarding the clinical non responders, Sollima et al. (22) suggested several hypotheses for delayed resolution of symptoms in patients with MCS after successful treatment of hepatitis $\mathrm{C}$, including greater severity and more advanced stage of vasculitis, delayed clearance of circulating cryoglobulins compared with $\mathrm{HCV}$ clearance, or incomplete suppression of B-cell clonal proliferation driving cryoglobulin production.

As regarding the clinical response in patients with fibromyalgia, the current study clears remarkable clinical betterment with significant lowering in symptom severity scale (SSS) $(\mathrm{p}<0.001)$, and wide-spread pain index (WPI) $(\mathrm{p}=0.005)$. Similar findings were reported by Mahmoud et al. $^{(23)}$, who enrolled 100 patients with fibromyalgia treated the same regimen, and found significant reduction in chronic widespread pain, $(\mathrm{p}=0.015)$ as well as VAS, $(\mathrm{p}=0.013)$.

Monaco et al. ${ }^{(24)}$ reported that HCV-related fibromyalgia disorders caused by up regulated host immune response accompanied by production of autoantibodies, immune complexes, and cryoglobulins. However, alternative mechanisms have also found a direct pathogenic role of the virus, and so down regulation of host immune response in patients who achieved spontaneous or treatment-induced viral clearance leads to improvements in neuropsychiatric and neurocognitive disorders.

Regarding the immunologic response to $\mathrm{HCV}$, the results of the present study showed a great immunologic activation (high circulating cryoglobulins, $\mathrm{RF}$, ANA, Anti-CCP, lower C4 and C3) in patients with $\mathrm{HCV}$ related rheumatic manifestations at base line. This finding is explained by that $\mathrm{Ab}$-secreting cell frequencies have been described as increased, consistent with polyclonal activation, whereas total B cell numbers are not substantially increased ${ }^{(25)}$.

In our study 50\% (30 out of 60) of patients were positive for cryoglobulin at base line and this is in consistence with Stefanova-Petrova et al. ${ }^{(26)}$.
Also, there were marked reduction in both number of positive patients and mean levels of all immune markers after treatment, $38.3 \%$ (23 out of 60 ) were positive for RF, $61.6 \%$ (37 out of 60) for ANA, $26.7 \%$ (16 out of 60) for Anti-CCP and 35\% (21out of 60 ) for cryoglobulin.

The study of Reyes-Avilés $\boldsymbol{e t}$ al. ${ }^{(27)}$, who observed that serum RF become lower after 8 weeks of treatment with IFN free therapy in comparison to baseline ( $\mathrm{p}=0.02)$ with $30 \%$ became negative for RF; and this was explained by the same authors, after treatment, proportions of mature activated memory B-cells of $\mathrm{HCV}$ $\mathrm{RF}+$ patients showed a slight decrease when compared to the baseline levels.

Furthermore, we noticed significant reduction in ANA positive patients at SVR12 only in virological responders in comparison to baseline with $37.2 \%$ (19 out of 51) of patients became negative for ANA after treatment; this is in agreement with the study of Sugiura et al. ${ }^{(28)}$.

Another important finding in the current study is that there was statistically significant decrease in cryoglobulin level (median baseline: $1.47 \mathrm{mg} / \mathrm{dl}$ versus SVR12: $1.02 \mathrm{mg} / \mathrm{dl}, \mathrm{p}=0.01$ ), with $34.6 \%$ (9 out of 26 ) became cryoglobulin negative at SVR12 only in virological responders, this similar to Bonacci et al. ${ }^{(15)}$ and Hassan et al. ${ }^{(29)}$, who found that all immunologic parameters improved at SVR12.

This was explained by the study of Saadoun $\boldsymbol{e t}$ al. ${ }^{(16)}$ who noticed that sofosbuvir based therapy is able to revert regulatory T-cell deficiency and expansion of $\mathrm{IgM}^{+} \mathrm{CD} 21$ memory B-cells, T-follicular helper cells, and Th17-cells in HCV-MCS patients that appear as appropriate to get a complete and sustained clearance of mixed- cryoglobulinemia.

Persistent of some immunological activity in short term follow up in our study presumably is due to persistence of the cryoglobulin producing memory B-cell clones, which have been shown to persist for at least 24 weeks in some patients successfully treated with DAAs $^{(30)}$.

Unlike our study, long post-treatment follow up ranged from 35-124 months (mean 92.5 months) in patients who achieve SVR in large cohort study has suggested that persistent cryoglobulinemia occurs only in $3 \%$ of patients with MCS $^{(31)}$.

Sise et al. ${ }^{(9)}$ also have reported in retrospective case series of twelve HCV- MCS patients that cryoglobulin levels decreased in most patients, with a median percent decreasing from $1.5 \%-0.5 \%$, and completely disappeared in $44.4 \%$ (4/9) cases.

Also, our results are supported by Saadoun $\boldsymbol{e t}$ al . (16), who observed that passing of cryoglobulin was completed in $45 \%-60 \%$ of MCS patients treated with DAAs.

\section{CONCLUSION}

It could be concluded that achieving sustained virologic response is the corner stone in improvement of 
$\mathrm{HCV}$ related rheumatic manifestations, this was reflected by both clinical and immunologic improvement of these manifestations after viral clearance among the studied group of Egyptian population.

\section{RECOMMENDATIONS}

A longer follow-up period after viral eradication might be necessary for Egyptian patients with HCV related rheumatic manifestations to assess long term efficacy of these regimens in achieving and maintaining clinical and immunologic response.

\section{Financial support and sponsorship: Nil. Conflict of interest: Nil.}

\section{REFERENCES}

1. Thomas D (2013): Global control of hepatitis C: where challenge meets opportunity. Nat Med., 19:850-8.

2. Ferri C, Sebastiani M, Giuggioli D et al. (2015): Hepatitis C virus syndrome: A constellation of organ- and nonorgan specific autoimmune disorders, B-cell nonHodgkin's lymphoma, and cancer. World J Hepatol., 7: 327-343.

3. Terrier B, Cacoub P (2013): Renal involvement in HCVrelated vasculitis. Clin Res Hepatol Gastroenterol., 37: 334_339.

4. Dammacco F, Sansonno D (2013): Therapy for hepatitis C virus-related cryoglobulinemic vasculitis. N Engl J Med., 369(11):1035-1045.

5. Ramos-Casals M, Zignego A, Ferri C et al. (2017): Evidencebased recommendations on the management of extrahepatic manifestations of chronic hepatitis $\mathrm{C}$ virus infection. J Hepatol., 66(6):1282-99.

6. Cacoub P, Poynard T, Ghillani P et al. (1999): Extrahepatic manifestations of chronic hepatitis C. MULTIVIRC Group. multidepartment virus C. Arthritis Rheum., 42:2204-12.

7. Himoto T, Masaki T (2012): Extrahepatic manifestations and autoantibodies in patients with hepatitis $\mathrm{C}$ virus infection. Clin Dev Immunol., 2012: 1-12.

8. Lawitz E, Sulkowski M, Ghalib R et al. (2014): Simeprevir plus sofosbuvir, with or without ribavirin, to treat chronic infection with hepatitis $\mathrm{C}$ virus genotype 1 in non-responders to pegylated interferon and ribavirin and treatment naïve patients: the COSMOS randomised study. Lancet, 384: 1756-1765.

9. Sise M, Allyson K, Wisocky J et al. (2016): Treatment of Hepatitis C Virus Associated Mixed Cryoglobulinemia with Direct-Acting Antiviral Agents. Hepatology, 63(2):408417.

10. Urraro T, Gragnani L, Piluso A et al. (2015): Combined treatment with antiviral therapy and rituximab in patients with mixed cryoglobulinemia: review of the literature and report of a case using direct antiviral agents-based antihepatitis $\mathrm{C}$ virus therapy. Case Reports Immunol., 15: 816-24.

11. Scott J, Gretch D (2007) Molecular diagnostics of hepatitis C virus infection: a systematic review. JAMA., 297:724-32.

12. Palazzi C, D'Amico E, D'Angelo $S$ et al. (2016): Rheumatic manifestations of hepatitis $\mathrm{C}$ virus chronic infection: Indications for a correct diagnosis. World J Gastroenterol., 22(4): 14051410.

13. Mukhtyar C, Lee R, Brown D et al. (2009): Modification and validation of the Birmingham Vasculitis Activity Score (version 3). Ann Rheum Dis., 68:1827-32.

14. Wolfe F, Clauw D, Fitzcharles $M$ et al. (2010): The American College of Rheumatology preliminary diagnostic criteria for fibromyalgia and measurement of symptom severity. Arthritis Care Res., 62 (5): 600-610.

15. Bonacci M, Sabela L, Londoño M et al. (2017): Virologic Clinical, and Immune Response Outcomes of Patients With Hepatitis C Virus-Associated Cryoglobulinemia Treated With Direct-Acting Antivirals. Clinical Gastroenterology and Hepatology. Clin Gastroenterol Hepatol., 15: 575-583.

16. Saadoun D, Thibault V, Si Ahmed S et al. (2016): Sofosbuvir plus ribavirin for hepatitis $\mathrm{C}$ virus-associated cryoglobulinaemia vasculitis: VASCUVALDIC study. Ann Rheum Dis., 75(10): 1777-82.

17. Cacoub P, Comarmond C, Fanny D et al. (2016): Extrahepatic manifestations of chronic hepatitis $\mathrm{C}$ virus infection. Ther Adv Infect Dis., 3(1): 3-14.

18. Pawlotsky J, Feld J, Zeuzem S et al. (2015): From non-A, nonB hepatitis to hepatitis C virus cure. J Hepatol., 62: 87-99.

19. Terrier B, Karras A, Cluzel $P$ et al. (2013): Presentation and prognosis of cardiac involvement in hepatitis $\mathrm{C}$ virus-related vasculitis. Am J Cardiol., 111: 265-72.

20. Sayiner Z, Haque U, Malik M et al. (2014): Hepatitis C virus infection and its rheumatologic implications. Gastroenterology \& Hepatology, 10(5): 287-93.

21. Gragnani L, Visentini M, Fognani E et al. (2016): Prospective study of guideline-tailored therapy with direct-acting antivirals for hepatitis $\mathrm{C}$ virus-associated mixed cryoglobulinemia. Hepatology, 64:1473-82.

22. Sollima S, Milazzo L, Peri A et al. (2016): Persistent mixed cryoglobulinaemia vasculitis despite hepatitis C virus eradication after interferon-free antiviral therapy. Rheumatology, 55:2084-85.

23. Mahmoud A, Okasha S, Hassan M et al. (2017): Response of fibromyalgia associated with Hepatitis C virus infection to combined oral antiviral therapy, Egypt. AMAJ., 2: 35-38.

24. Monaco S, Mariotto S, Ferrari S, Calabrese M, Zanusso G, et al. (2015): Hepatitis $C$ virus-associated neurocognitive and neuropsychiatric disorders: Advances in. World J Gastroenterol .21:11974-11983

25. Rosa D, Saletti G, De Gregorio E et al. (2005): Activation of naive B lymphocytes via CD81, a pathogenetic mechanism for hepatitis C virus-associated B lymphocyte disorders. Proc Natl Acad Sci USA., 102: 18544-18549.

26. Stefanova-Petrova D, Tzvetanska A, Naumova A et al., (2007): Chronic hepatitis C virus infection: prevalence of extrahepatic manifestations and association with cryoglobulinemia in Bulgarian patients. World Journal of Gastroenterology, 13: 6518-6528.

27. Reyes-Avilés E, Kostadinova L, Rusterholtz A et al. (2015): Presence of rheumatoid factor during chronic HCV infection isassociated with expansion of mature activated memory B-cells that are hypo-responsive to B-cell receptor stimulation and persist during the early stage of IFN free therapy. PLoS One, 10:1-16.

28. Sugiura A, Wada S, Mori H et al. (2017): Successful Treatment for Chronic Hepatitis C-Autoimmune Hepatitis Overlap Syndrome due to Daclatasvir and Asunaprevir. Case Rep Gastroenterol., 11:305-311.

29. Hassan M, Osman H, Mahmoud H et al. (2018): Sofosbuvirdaclatasvir improves hepatitis C virus-induced mixed cryoglobulinemia: Upper Egypt experience. Infection and Drug Resistance, 11: 895-901.

30. Del Padre M, Todi L, Mitrevski M et al. (2017): Reversion of anergysignatures in clonal CD21low B cells of mixed cryoglobulinemia after clearance of HCV viremia. Blood, 130:3538.

31. Gragnani L, Fognani E, Piluso A et al. (2015): Long-term effect of HCV eradication in patients with mixed cryoglobulinemia: a prospective, controlled, open-label, cohort study. Hepatology, 61:1145-53. 